\title{
Experimental and Numerical Study on Bar-Reinforced Concrete Filled Steel Tubular Columns Under Axial Compression
}

\author{
Jinsheng Han* and Shuping Cong
}

School of Civil Engineering and Architecture, Shandong University of Science and Technology, Qingdao 266510, China

\begin{abstract}
The behaviors of bar-reinforced concrete filled steel tubular columns subjected to axial load were studied. One plain concrete filled steel tubular column and three bar-reinforced concrete filled steel tubular columns were tested. The deformation of specimens and the strain of steel tubes were measured. Based on experimental researches, a simple numerical analysis method was presented to simulate the full load-deformation process of bar-reinforced concrete filled steel tubular short columns subjected to axial compression. Firstly, the interaction process of steel tube and concrete was analyzed, and then, the simplified constitutive models of steel tube and concrete were established on the base of previous analysis results. Secondly, the relation between lateral and longitudinal strain of steel tube was analyzed based on experimental results, and a simple method was presented to calculate the lateral strain of steel tube. This method was used as the supplement to the constitutive models. Finally, a program was worked out to simulate the full load-deformation process of bar-reinforced concrete filled steel tubular short columns. The program's simulation results of both ultimate bearing capacity and load-deformation curves are in good agreement with the experimental results.
\end{abstract}

Keywords: Bar-reinforced concrete filled steel tubular column, test, Interaction, Constitutive models, Load-deformation process, Numerical simulation.

\section{INTRODUCTION}

Bar-reinforced concrete filled steel tubular (CFST) columns have a good advantage that they can satisfy the practical need of fire resistance depending on the fireresistant ability of themselves, so the external fire-proof protection layers are not necessary. As a result, a lot of investigations have been carried out to research the fire resistance and ultimate bearing capacity of bar-reinforced CFST columns [1-3]. However, researches on the full process of force-deformation of CFST column are relatively scarce. Bar-reinforced CFST column is a typical confined concrete because the core concrete is confined by steel tube. Many of the previous research works on confined concrete have been mainly focused on the concrete confined by transverse reinforcement [4-7] or FRP [8-10]. It is very easy to determine the confinement pressure which is corresponding to the yield strength of transverse reinforcement or FRP. But it is very different for barreinforced CFST short columns which are confined by steel tubes. Firstly, the confinement effect doesn't exist at the early stage of loading just as discussed as follows. Secondly, after the appearance of the interaction between concrete and steel tube, the lateral strain of steel tube needs to be previously known to determine the stress of steel tube. The lateral strain of steel tube is determined by the lateral dilatational strain of core concrete, in turn, the dilatational

*Address correspondence to this author at the School of Civil Engineering and Architecture, Shandong University of Science and Technology, Qingdao 266510, China; Tel: +86-0532-86055792;

Fax: +86-0532-87199217; E-mail: hjsheng2008@163.com strain of core concrete is influenced by the confinement pressure from steel tube. So the core concrete and steel tube interact and affect each other, and it's very difficult and complex to determine the lateral strain of steel tube and calculate the stress state of steel tube and core concrete. Based on experimental researches, the relation between lateral and longitudinal strain of steel tube was analyzed, and a simple method was presented to calculate the lateral strain of steel tube and simulate the full load-deformation process of bar-reinforced CFST short columns subjected to axial compression.

\section{EXPERIMENTAL STUDY}

In order to study the behaviors of CFST columns subjected to axial load, one plain concrete filled steel tubular column and three bar-reinforced concrete filled steel tubular columns were tested. The diameter of longitudinal reinforcing bars is $20 \mathrm{~mm}$. The measured yield strength of longitudinal reinforcing bars is $493 \mathrm{MPa}$ and that of shear reinforcement is about $230 \mathrm{MPa}$. The parameters of the test specimens are listed in Table $\mathbf{1}$, and the details of the specimens are shown in Fig. (1).

A series of strain rosettes were pasted at the upper, middle and lower parts of the steel tubes as shown in Fig. (1) to measure the longitudinal and lateral strains of steel tubes. At each part, there were four strain rosettes called as A B C $\mathrm{D}$ respectively. For convenience, the lateral strain measured by each strain rosette is labeled as " 1 " and the longitudinal strain is labeled as "2". For example, "A1" indicates the lateral strain measured by the strain rosette " $\mathrm{A}$ ". 
Table 1. Parameters of Test Specimens

\begin{tabular}{|c|c|c|c|c|c|c|c|c|c|}
\hline \multirow{2}{*}{ Number } & \multirow{2}{*}{$\begin{array}{l}\text { Height } \\
H / \mathrm{mm}\end{array}$} & \multirow{2}{*}{$\begin{array}{c}\text { Outer } \\
\text { Diameter } \\
D / \mathbf{m m}\end{array}$} & \multirow{2}{*}{$\begin{array}{c}\text { Thickness of } \\
\text { Steel Tube } \\
t / \mathrm{mm}\end{array}$} & \multirow{2}{*}{$\begin{array}{c}\text { Strength of } \\
\text { Concrete } \\
f_{\mathrm{ck}}^{\prime} / \mathrm{MPa}\end{array}$} & \multirow{2}{*}{$\begin{array}{c}\text { Strength of } \\
\text { Steel Tube } \\
f_{\mathrm{sk}} / \mathrm{MPa}\end{array}$} & \multicolumn{2}{|c|}{ Longitudinal Reinforcement } & \multirow{2}{*}{$\begin{array}{c}\text { Shear } \\
\text { Reinforce- } \\
\text { ment }\end{array}$} & \multirow{2}{*}{$\begin{array}{c}\text { Ultimate Bearing } \\
\text { Capacity } \\
N_{\mathrm{ue}} / \mathbf{k N}\end{array}$} \\
\hline & & & & & & Quantity & $\begin{array}{c}\text { Thickne-ss of } \\
\text { Concrete Cover } c / \mathrm{mm}\end{array}$ & & \\
\hline A1 & 900 & 300 & 5.5 & 49.0 & 336 & 0 & - & 0 & 5385 \\
\hline $\mathrm{A} 2$ & 900 & 300 & 4.3 & 49.0 & 376 & $6 Ф 20$ & 70 & Ф10@150 & 6641 \\
\hline $\mathrm{A} 3$ & 900 & 300 & 4.3 & 52.2 & 376 & $6 \Phi 20$ & 70 & Ф10@150 & 6718 \\
\hline A4 & 900 & 300 & 4.3 & 52.2 & 376 & $8 Ф 20$ & 65 & Ф10@150 & 7385 \\
\hline
\end{tabular}

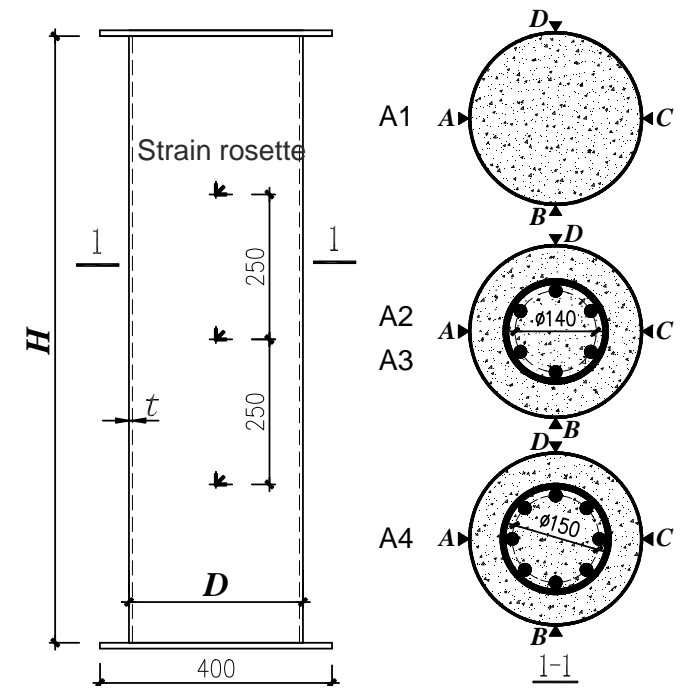

Fig. (1). Details of specimens.

The relation curves for specimens between axial load and axial average strain measured by displacement gauges are shown in Fig. (2). Two typical test results of longitudinal and lateral strain of steel tubes corresponding to axial load are shown in Fig. (3). Furthermore, the lateral-axial strain curves for steel tubes are shown in Fig. (5).

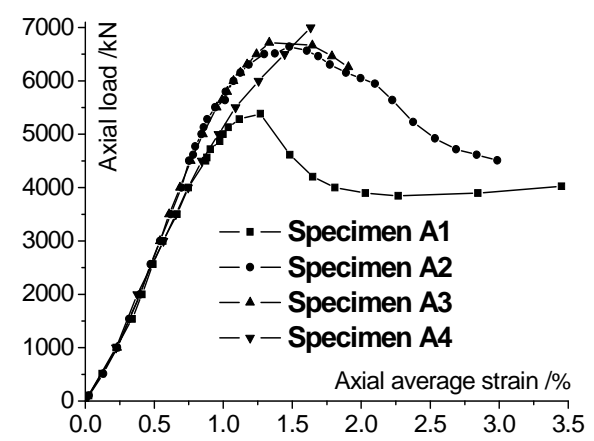

Fig. (2). Axial load-axial average strain curves for specimens.

\section{LOAD-DEFORMATION PROCESS ANALYSIS}

The load-deformation process of CFST columns subjected to axial compression is an interacting process among steel tube and core concrete, which can be simplified as three stages as below.

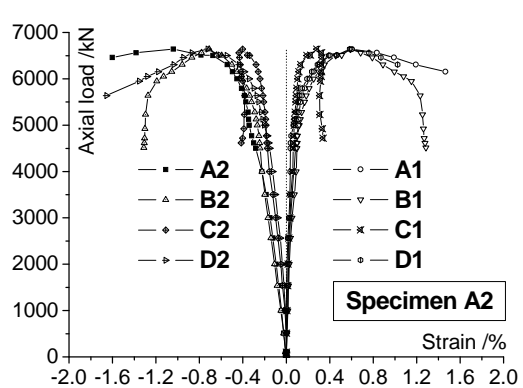

(a)

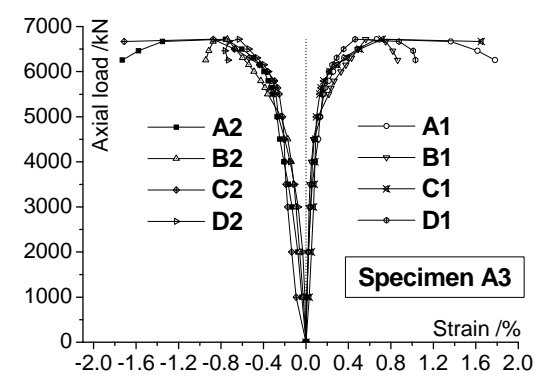

(b)

Fig. (3). Measured strain of steel tubes for (a) Specimen A2 and (b) Specimen A3.

The first stage is that the steel tube and core concrete work independently. At the beginning, the transversal strain of steel tube is bigger than that of core concrete because the steel tube has no effect on core concrete owing to the fact that the Poisson ratio of steel tube is also higher than that of core concrete. There is no confinement effect between concrete and steel tube at the initial loading stage. However, the Poisson ratio of core concrete increases greatly due to the increase of the load. Therefore, the Poisson's ratio of concrete will be finally equal to that of steel tube at the state $I_{\mathrm{a}}$, when the interaction between concrete and steel tube just is occurring. At this time, the axial deformation of the column is normally smaller than the peak strain $\varepsilon_{\mathrm{co}}$ of unconfined concrete, and both the steel tube and the concrete still remain in elastic conditions. After state $I_{a}$, the steel tube is in lateral and longitudinal plane stress state, and the core concrete is in compression stressed condition in tripdirections. 
The second stage is before the peak strain of core concrete confined by steel tube. At this stage, the stress of steel tube passes from elastic state to plastic state. In plastic state, the lateral stress of steel tube will steadily increase while the longitudinal stress decreases. At the same time, the axial compressive strength and deformation capability of core concrete, corresponding to the peak stress and peak strain, increase gradually because of the significant confinement of steel tube. Since the lateral stress of steel tube is variable in the compress process, the peak stress and peak strain of core concrete is also in the process of dynamic growth. But the increase speed of the peak strain of core concrete is smaller than the axial compressive strain of the column. Ultimately, the peak strain of core concrete confined by steel tube is equal to the axial compressive strain of the column, and the critical state $\mathrm{II}_{\mathrm{a}}$ arrives. At this stage, the longitudinal stress of steel tube increases before plastic condition and decreases after plastic condition, while the lateral stress of steel tube and the stress of core concrete increase continuously. In a certain state before core concrete reaches its peak strain, the sum of the bearing capacity of core concrete and steel tube reaches maximum, which is the ultimate strength of the column.

The third stage is after the peak strain of core concrete confined by the steel tube. After the second stage, the stress of core concrete decreases with the strain increases even though the confinement pressure still increases. At this stage, the longitudinal stress of steel tube and core concrete decrease continuously. Therefore, the strength of the column is decreasing until the column is crushed.

\section{THEORY OF NUMERICAL ANALYSIS}

\subsection{Basic Assumptions}

(1) At the initial loading stage, both core concrete and steel tube are compressed independently. There is no steelconcrete interaction.

(2) After core concrete begins to be confined by steel tube, the steel tube is in plane stress state and Mises yield rule can be used to determine the stress-strain relationship. At the same time, the core concrete is in triaxial compressive stress state owing to the confinement of steel tube. The stress in the column section is uniformly distributed.

(3) Because the confinement effect applied to core concrete by steel tube is uniform in any direction, the radial strain and hoop strain of core concrete are equal, and the lateral strain of steel tube and the hoop strain of core concrete are also equal.

(4) Superposition method is used to consider the effect of longitudinal reinforcements for the ultimate bearing capacity of the column. But the effect of the stirrup is ignored.

\subsection{Simplified Stress-Strain Relationships of Core Concrete and Steel Tube Core Concrete}

The stress-strain relationships of unconfined concrete and confined concrete are shown in Fig. (4) [11]. The expression for the stress-strain curve of confined concrete is defined as suggested by Popovics (1973), which is later modified by Mander (1984) and is given by the following expression 4:

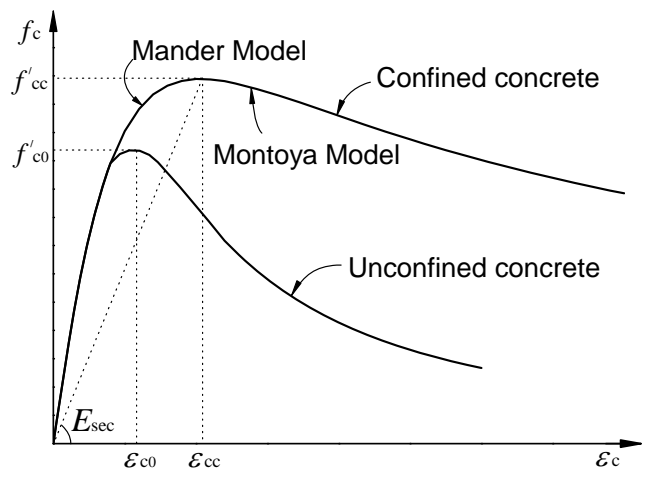

Fig. (4). General stress-strain curves for unconfined and confined concrete.

$$
\begin{aligned}
f_{\mathrm{c}} & =\frac{f_{\mathrm{cc}}^{\prime} x r}{r-1+x^{r}} \\
\varepsilon_{\mathrm{cc}} & =\varepsilon_{\mathrm{c} 0}\left[1+5\left(f_{\mathrm{cc}}^{\prime} / f_{\mathrm{c} 0}^{\prime}-1\right)\right]
\end{aligned}
$$

Where $f_{\mathrm{c}}$ and $\varepsilon_{\mathrm{c}}$ denote the longitudinal compressive stress and strain, respectively; $f_{\mathrm{cc}}^{\prime}$ and $\varepsilon_{\mathrm{cc}}$ are the peak stress and peak strain of confined concrete respectively; $x=\varepsilon_{\mathrm{c}} / \varepsilon_{\mathrm{cc}}$; $r=E_{\mathrm{c}} /\left(E_{\mathrm{c}}-E_{\mathrm{sec}}\right) ; \quad E_{\mathrm{sec}}=f_{\mathrm{cc}}^{\prime} / \varepsilon_{\mathrm{cc}} ; \quad E_{\mathrm{c}}=5000 \sqrt{f_{\mathrm{c} 0}^{\prime}} \mathrm{MPa} ;$ $\varepsilon_{\mathrm{c} 0}$ and $f_{\mathrm{c} 0}^{\prime}$ stand for the peak strain and peak stress of unconfined concrete.

Based on the William-Warnke failure criterion, the peak stress of confined concrete with uniform lateral restraint can be derived as follows:

$$
f_{\mathrm{cc}}^{\prime}=f_{\mathrm{c} 0}^{\prime}\left(-1.254+2.254 \sqrt{1+7.94 f_{l} / f_{\mathrm{c} 0}^{\prime}}-2 f_{l} / f_{\mathrm{c} 0}^{\prime}\right)
$$

Where $f_{l}$ denotes the hoop stress (confinement pressure) caused by steel tube, corresponding to the peak strain of confined concrete.

The post-peak region of equation (1) is not used and displaced by the expression suggested by Montoya (2004) [5], which is given by

$$
f_{\mathrm{c}}=\frac{f_{\mathrm{cc}}^{\prime}}{A\left(\varepsilon_{\mathrm{c}} / f_{\mathrm{cc}}^{\prime}\right)^{2}-B\left(\varepsilon_{\mathrm{c}} / f_{\mathrm{cc}}^{\prime}\right)+C+1.0}
$$

Where $\quad A=0.25\left(f_{\mathrm{cc}}^{\prime} /\left(\varepsilon_{\mathrm{c} 80}-\varepsilon_{\mathrm{cc}}\right)\right)^{2} ; \quad B=2 A / E_{\mathrm{sec}}$; $C=A / E_{\mathrm{sec}}^{2} ; \varepsilon_{\mathrm{c} 80}$ stands for the strain in post-peak region corresponding with $0.8 f_{\mathrm{cc}}^{\prime}$, which can be given by

$$
\varepsilon_{\mathrm{c} 80}=\varepsilon_{\mathrm{c} 0}\left(1.5+\left(89.5-0.60 f_{\mathrm{c} 0}^{\prime}\right) f_{l} / f_{\mathrm{c} 0}^{\prime}\right)
$$

\section{Steel Tube}

The stress-strain relationships of steel tube in pre-yield state can be given by

$$
\left\{\begin{array}{c}
\sigma_{\mathrm{z}} \\
\sigma_{L}
\end{array}\right\}=\frac{E_{\mathrm{s}}}{1-v_{\mathrm{s}}^{2}}\left[\begin{array}{cc}
1 & v_{\mathrm{s}} \\
v_{\mathrm{s}} & 1
\end{array}\right]\left\{\begin{array}{l}
\varepsilon_{\mathrm{z}} \\
\varepsilon_{L}
\end{array}\right\}
$$


The incremental stress-strain relationships of steel tube in post yield state can be given by

$\left\{\begin{array}{l}d \sigma_{\mathrm{z}} \\ d \sigma_{L}\end{array}\right\}=\left\{\frac{E_{\mathrm{s}}}{1-v_{\mathrm{s}}^{2}}\left[\begin{array}{cc}1 & v_{\mathrm{s}} \\ v_{\mathrm{s}} & 1\end{array}\right]-\frac{1}{S}\left[\begin{array}{cc}t_{\mathrm{z}}^{2} & t_{\mathrm{z}} t_{L} \\ t_{\mathrm{z}} t_{L} & t_{L}^{2}\end{array}\right]\right\}\left\{\begin{array}{l}d \varepsilon_{\mathrm{z}} \\ d \varepsilon_{L}\end{array}\right\}$

where subscript $z$ and $L$ stand for the longitudinal and lateral directions respectively; $E_{\mathrm{s}}$ and $v_{\mathrm{s}}$ are the elastic modulus and Poisson ratio of steel tube respectively; $s_{\mathrm{z}}$ and $s_{L}$ are the longitudinal and lateral stress deviators of steel tube respectively; $S=t_{\mathrm{z}} S_{\mathrm{z}}+t_{L} S_{L} ; t_{\mathrm{z}}=\frac{E_{\mathrm{s}}}{1-v_{\mathrm{s}}^{2}}\left(\frac{2-v_{\mathrm{s}}}{3} \sigma_{\mathrm{z}}+\frac{2 v_{\mathrm{s}}-1}{3} \sigma_{L}\right)$; $t_{L}=\frac{E_{\mathrm{s}}}{1-v_{\mathrm{s}}^{2}}\left(\frac{2-v_{\mathrm{s}}}{3} \sigma_{L}+\frac{2 v_{\mathrm{s}}-1}{3} \sigma_{\mathrm{z}}\right)$

It can be seen from the simplified stress-strain relationships that the stress of steel tube and the confinement pressure of core concrete can be determined if the longitudinal and lateral deformations have been known. Then, the stress-strain relationships of core concrete can be also determined. So the key question is how to determine the deformation process of steel tube.

\subsection{Analysis and Simplified Treatment for the Deformation of Steel Tube}

As discussed above, the core concrete and steel tube interact and affect each other, and it's very difficult to determine the lateral strain of steel tube and calculate the stress state of steel tube and core concrete. In order to simplify the analytical process, four bar-reinforced CFST short columns were experimented to study the stress-strain relationships of steel tube and core concrete. The experimental results, a lot of lateral-axial strain curves for steel tubes, are shown in Fig. (5). If the longitudinal and lateral strain of steel tube, corresponding to the stage $I_{a}$ and stage $\mathrm{II}_{\mathrm{a}}$, are $\varepsilon_{\mathrm{z} 0}, \varepsilon_{L 0}$ and $\varepsilon_{c c}, \varepsilon_{L c}$ respectively, the lateralaxial strain curves can be classified into three sections respectively corresponding to the three stages analyzed above. These three sections can be simply treated based on the experimental results.

At stage I, there is no interaction between core concrete and steel tube. The steel tube is in elastic state and its lateral strain is given by

$\varepsilon_{L}=v_{\mathrm{s}} \varepsilon_{\mathrm{z}}$

And $\varepsilon_{L 0}=v_{s} \quad \varepsilon_{\mathrm{z} 0}$

At stage III, the stress-strain relationship of core concrete is in post-peak region. The relation between lateral and longitudinal strain of steel tube can be considered as linear relation with a constant slope of $k$ approximately. So the expression can be given as

$\varepsilon_{L}=k\left(\varepsilon_{\mathrm{z}}-\varepsilon_{\mathrm{cc}}\right)+\varepsilon_{L \mathrm{c}}$

At stage II, the strain of steel tube increases quickly. Refer to the test results, the strain of steel tube can be expressed as cubic equation as follow,
$\varepsilon_{L}=a \varepsilon_{\mathrm{z}}^{3}+b \varepsilon_{\mathrm{z}}^{2}+c \varepsilon_{\mathrm{z}}+d$

Where, $a, b, c$ and $d$ are four coefficients which can be determined by two separation points, tangent slopes at the start point and at the end point of this cubic curve. It is needed to notice that the coordinate values and the tangent slopes of the start and end point are variable corresponding to the specific constructional conditions of the CFST columns. Therefore, the relationship curves are not constant but are needed to be determined in calculating process.

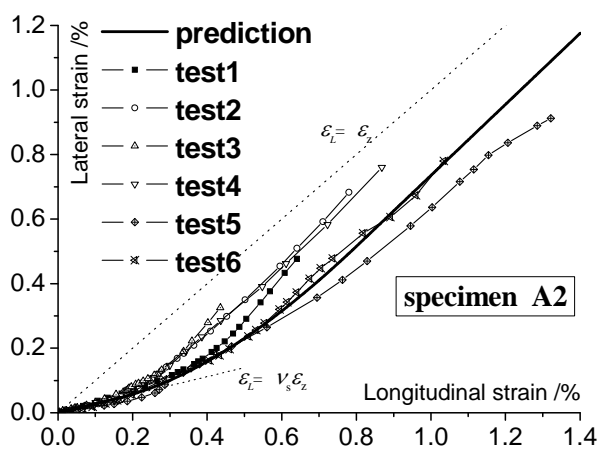

(a)

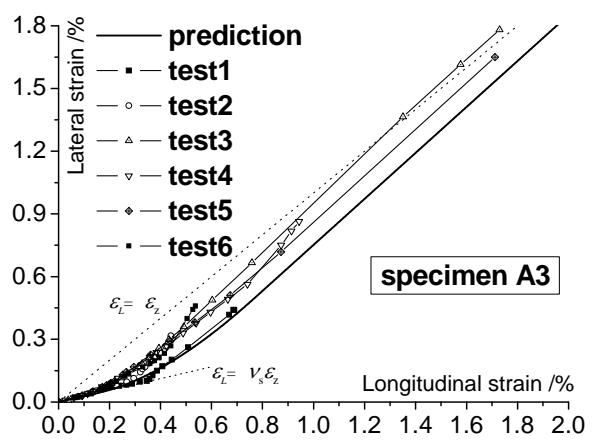

(b)

Fig. (5). Lateral-axial strain curves of steel tubes for (a) Specimen A2 and (b) Specimen A3.

Moreover, three special values must be determined primarily in order to establish the stress-strain relationship of steel tube completely.

(1) The longitudinal strain $\varepsilon_{z 0}$ when the interaction between core concrete and steel tube is just occurring. The strain is corresponding to the stage $I_{a}$, when the secant Poisson ratio $v_{c}$ of concrete is equal to the Poisson ratio $v_{s}$ of steel tube. According to Ottosen model, the secant Poisson ratio of concrete is given by

$$
\left\{\begin{array}{lr}
v_{\mathrm{c}}=v_{i} ; & \beta \leq 0.8 \\
v_{\mathrm{c}}=v_{f}-\left(v_{f}-v_{i}\right) \sqrt{1-(5 \beta-4)^{2}} ; & 0.8<\beta \leq 1.0
\end{array}\right.
$$

Where, $\beta=f_{\mathrm{c}} / f_{\mathrm{cc}}^{\prime} ; v_{f}$ is the peak Poisson ratio of concrete; $v_{i}$ is the original Poisson ratio of concrete, which is presented by Candappa (2001) and is given by the following expression [12]: 
$v_{i}=8 \times 10^{-6}\left(f_{\mathrm{c} 0}^{\prime}\right)^{2}+0.0002 f_{\mathrm{c} 0}^{\prime}+0.138$

If $v_{c}=v_{s}$, the ratio $\beta$ between the stress of confined concrete and unconfined concrete can be derived from equation (11). In turn, $\varepsilon_{z 0}$ can be determined by the uniaxial stress-strain relationships of unconfined concrete.

(2) The peak strain $\varepsilon_{c c}$ of confined concrete.

The strain $\varepsilon_{c c}$, corresponding to the stage $\mathrm{II}_{\mathrm{a}}$, can be derived by $f_{\text {cc }}^{\prime}$ from equation (2). While the peak stress $f_{\text {cc }}^{\prime}$ of confined concrete can be determined by the hoop pressure $f_{l}$, which is given by

$$
f_{l}=\beta^{\prime} \frac{2 t}{D-2 t} f_{\mathrm{sk}}
$$

Where $D$ and $t$ are the outer diameter and thickness of steel tube respectively; $f_{s k}$ is the uniaxial yield strength of steel tube; $\beta^{\prime}$ is the coefficient of hoop pressure corresponding to the peak strain of concrete. The calculating equation for $\beta^{\prime}$, in [13], was given by

$\beta^{\prime}=v_{e}-v_{s}$

But, the hoop pressure $f_{l}$ derived from equation (13) and equation (14) is only an initial approximate value and the accurate value must be determined in the numerical iterative process.

(3) The lateral strain $\varepsilon_{L c}$ corresponding to the peak strain of confined concrete.

The relation between the lateral strain and peak strain of confined concrete, given by Lokuge (2004) [14], is $\varepsilon_{L c}=0.5 \varepsilon_{c c}$. But this result is based on the tests of confined concrete with constant triaxial pressure. In fact, the hoop pressure of core concrete in CFST column is gradually increasing. Therefore, the lateral strain corresponding to the peak strain of core concrete should be a little larger. The following expression is used in this paper to determine the lateral strain $\varepsilon_{L c}$.

$$
\varepsilon_{L \mathrm{c}}=0.65 \varepsilon_{\mathrm{cc}}
$$

\section{NUMERICAL SIMULATION FOR THE WHOLE LOAD-DEFORMATION PROCESS}

The concrete strength is taken as $0.85 f_{\mathrm{c} 0}^{\prime}$ in order to take into account the strength difference between concrete test cubes and test specimens [13]. And the strength of steel tube is taken as $0.85 f_{\text {sk }}$ in order to take into account the effects of non-uniform stress distribution and local buckling. Furthermore, other parameters used in the numerical simulation are taken as $E_{\mathrm{s}}=2.0 \times 10^{5} \mathrm{MPa} \varepsilon_{c 0}=0.002 \quad v_{s}=0.28$ $v_{f}=0.5 k=1.1$.

In the numerical calculation process, the axial strain of the column increases gradually from zero in order to determine the stress-strain relationships of core concrete and steel tube. Furthermore, the axial force of the column can be worked out and the whole load-deformation process can be obtained. A key step in the calculation procedure is to determine the hoop pressure corresponding to the peak strain of confined core concrete to establish the stress-strain relationships of core concrete and steel tube.

Based on the foregoing analysis results, one program has been developed to simulate the full load-deformation process of bar-reinforced CFST short columns under axial compression. The simulation results of the longitudinal and lateral strain of steel tube, and the comparison between the simulation results and test results, are shown in Fig. (5). The deformation comparison of two bar-reinforced CFST columns between calculating results and experimental results are shown in Fig. (6). Furthermore, some calculating and experimental results of the ultimate bearing capacity of CFST columns, including the ratio of calculating data to testing data, are listed in Table $\mathbf{2}$.

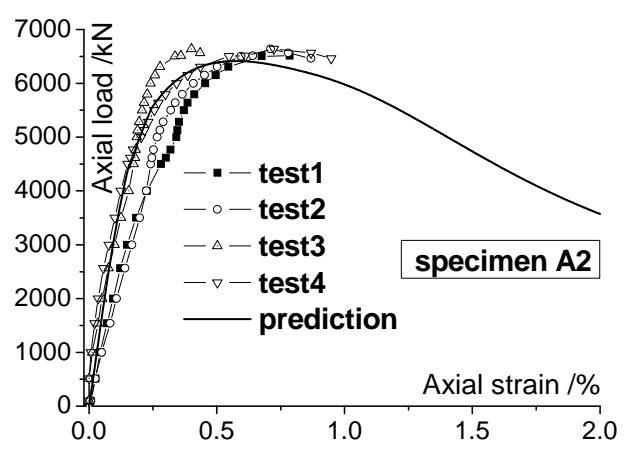

(a)

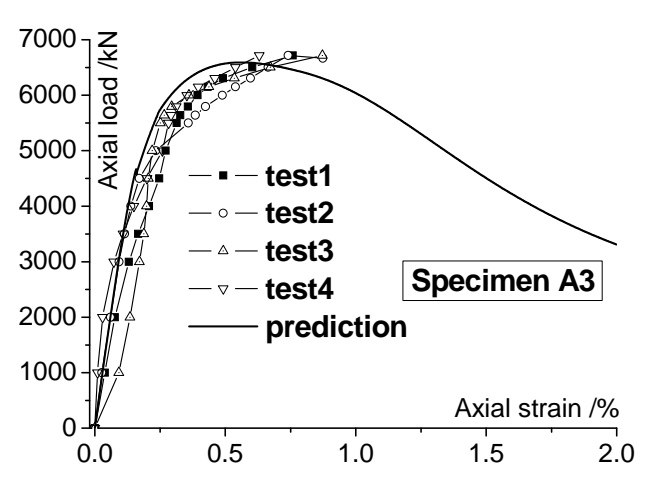

(b)

Fig. (6). Comparison of deformation between simulations and tests for (a) Specimen A2 and (b) Specimen A3.

It can been clearly seen from the comparison of calculating results with experimental results that the method presented to analyze the longitudinal and lateral strain of steel tube is feasible and practicable. Moreover, the program also has a good accuracy to simulate the load-deformation process and calculate the ultimate bearing capacity of CFST columns. 
Table 2. Comparison of Ultimate Strength of CFST Columns Between Experimental Results and Simulation Results

\begin{tabular}{|c|c|c|c|c|c|c|c|c|c|}
\hline Source & Number & $\begin{array}{c}\text { Outer Diameter } \\
\text { of Steel Tube } \\
\text { D/mm }\end{array}$ & $\begin{array}{c}\text { Thickness of } \\
\text { Steel Tube } \\
t / \mathrm{mm}\end{array}$ & $\begin{array}{c}\text { Strength of } \\
\text { Steel Tube } \\
f_{\text {sk }} / \mathrm{MPa}\end{array}$ & $\begin{array}{c}\text { Strength of } \\
\text { Concrete } \\
f_{\mathrm{ck}}^{\prime} / \mathrm{MPa}\end{array}$ & $\begin{array}{c}\text { Height of } \\
\text { Specimen } \\
\text { H/mm }\end{array}$ & $\begin{array}{c}\text { Test } \\
\text { Strength } \\
N_{\mathrm{ue}} / \mathrm{kN}\end{array}$ & $\begin{array}{c}\text { Prediction } \\
\text { Strength } \\
N_{\mathrm{uc}} / \mathbf{k N}\end{array}$ & $\begin{array}{l}\text { Ratio of } \\
\text { Strength } \\
N_{\text {ud }} / N_{\text {ue }}\end{array}$ \\
\hline \multirow{9}{*}{ [15] } & SB2 & 630 & 7.0 & 291 & 36.0 & 1890 & 16650 & 16683 & 1.002 \\
\hline & SB3 & 630 & 10.21 & 323 & 38.4 & 1890 & 20500 & 21346 & 1.041 \\
\hline & SB4 & 630 & 11.6 & 347 & 46.0 & 1890 & 24400 & 25488 & 1.045 \\
\hline & SB5 & 720 & 8.3 & 312 & 15.0 & 2160 & 15000 & 15385 & 1.026 \\
\hline & SB6 & 630 & 7.61 & 350 & 35.0 & 1890 & 18000 & 18404 & 1.022 \\
\hline & SB7 & 630 & 8.44 & 350 & 34.5 & 1890 & 18600 & 19241 & 1.034 \\
\hline & SB8 & 820 & 8.93 & 331 & 45.0 & 2460 & 33600 & 33268 & 0.990 \\
\hline & SB9 & 1020 & 9.64 & 336 & 16.9 & 3060 & 30000 & 30182 & 1.006 \\
\hline & SB10 & 1020 & 13.25 & 369 & 28.9 & 3060 & 46000 & 47086 & 1.024 \\
\hline [16] & CFST & 300 & 5.0 & 478 & 53.0 & 900 & 7000 & 6788 & 0.970 \\
\hline \multirow{4}{*}{$\begin{array}{l}\text { This } \\
\text { paper }\end{array}$} & $\mathrm{A} 1$ & 300 & 5.5 & 336 & 49.0 & 900 & 5385 & 5860 & 1.088 \\
\hline & A2 & 300 & 4.3 & 376 & 49.0 & 900 & 6641 & 6415 & 0.966 \\
\hline & A3 & 300 & 4.3 & 376 & 52.2 & 900 & 6718 & 6592 & 0.981 \\
\hline & A4 & 300 & 4.3 & 376 & 52.2 & 900 & 7385 & 6902 & 0.935 \\
\hline
\end{tabular}

\section{SUMMARY}

In order to study the behaviors of CFST columns subjected to axial load, one plain concrete filled steel tubular column and three bar-reinforced concrete filled steel tubular columns were tested. The deformation of specimens and the strain of steel tubes were measured. A simple numerical analysis method has been presented to simulate the full loaddeformation process of bar-reinforced CFST short columns subjected to axial compression. The interaction process of steel tube and core concrete is analyzed, and it is obvious that it's very difficult and complex to determine the strain and stress of steel tube and core concrete because they are independent and influence each other. For simplicity, a simple method is presented based on experimental researches to calculate the strain of steel tube, and further to calculate the stress of core concrete and steel tube. A program is worked out to analyze the full load-deformation process of bar-reinforced CFST short columns based on above researching results. The prediction results of the program for both ultimate bearing capacity and load-deformation curves show good agreement with different test results.

\section{ACKNOWLEDGMENTS}

This work was financially supported by the Promotive Research Fund for Excellent Young and Middle-aged Scientists of Shandong Province (BS2010SF022).

\section{REFERENCES}

[1] G. Georgios, and L. Dennis, "Axial capacity of circular concretefilled tube columns", J. Constr. Steel Res., vol. 60, pp.1049-1068, July 2004
[2] Q. X. Wang, D. Z. Zhao, and P. Guan, "Experimental study on the strength and ductility of steel tubular columns filled with steel-reinforced concrete", Eng. Struct., vol. 26, pp. 907-915, June 2004.

[3] P. K. Gupta, S. M. Sarda, and M. S. Kumar, "Experimental and computational study of concrete filled steel tubular columns under axial loads", J. Constr. Steel. Res., vol. 63, pp. 182-193, February 2007.

[4] J. B. Mander, M. J. N. Priestley, and R. Park, "Theoretical stressstain model for confined concrete", J. Struct. Eng., vol. 114 pp. 1804-1826, 1998.

[5] E. Montoya, F. J. Vecchio, and S. A. Sheikh, "Numerical evaluation of the behaviour of steel- and FRP-confined concrete columns using compression filed modeling", Eng. Struct., vol. 26, pp.1535-1545, September 2004.

[6] C. Daniel, and P. Patrick, "Stress-strain model for confined high strength concrete", J. Struct. Eng., vol. 121, pp. 468-477, 1995.

[7] G. Campione, and L. L. Mendola, "Behavior in compression of lightweight fiber reinforced concrete confined with transverse steel reinforcement", Cement Concr. Comp., vol. 26, pp. 645-656, August 2004.

[8] L. Lam, and J. G. Teng, "Stress-strain model for FRP-confined concrete under cyclic axial compression", Eng. Struct., vol. 31, pp. 308-321, February 2009.

[9] E. Vintzileou, and E. Panagiotidou, "An empirical model for predicting the mechanical properties of FRP-confined concrete", Constr. Build. Mater., vol. 22, pp. 841-854, May 2008.

[10] T. Jiang, and J. G. Teng, "Analysis-oriented stress-strain models for FRP-confined concrete", Eng. Struct., vol.29, pp. 2968-2986, November 2007

[11] G. D. Hatzigeorgiou, "Numerical model for the behavior and capacity of circular CFT columns, Part I: Theory", Eng. Struct., vol. 30, pp.1573-1578, June 2008.

[12] D. P. Candappa, J. G. Sanjayan, S. Setunge, and J. Mater, "Complete triaxial stress-strain curves of high-strength concrete", $J$. Mater. Civil Eng., vol. 13, pp. 209-215, 2001.

[13] K. A. S. Susantha, G. Hanbin, and U. Tsutomu, "Uniaxial stress-strain relationship of concrete confined by various shaped steel tubes", Eng. Struct., vol. 23, pp. 1331-1347, October 2001 . 
[14] W. P. Lokuge, J. G. Sanjayan, and S. Setunge, "Constitutive model for confined high strength concrete subjected to cyclic loading", $J$. Mater. Civil Eng., vol. 16, pp. 297-305, 2004.

[15] C. D. Goode, "Concrete filled steel tubular columns-state of the art", Indus. Con., vol. 26, pp. 23-27, 1996 (in Chinese).
[16] C. M. Zhang, L. C. Wang, and Y. Yin, "Studies on axial compressive experiments of several kinds of steel and high-strength concrete columns", J. Harbin Inst. Tech., vol. 36, pp. 1678-1682, 2004 (in Chinese).

Received: September 09, 2010

(C) Han and Cong; Licensee Bentham Open.

This is an open access article licensed under the terms of the Creative Commons Attribution Non-Commercial License

(http://creativecommons.org/licenses/_by-nc/3.0/) which permits unrestricted, non-commercial use, distribution and reproduction in any medium, provided the work is properly cited. 